\title{
Pragmatic Failure in the Realization of the Speech act of Responding to Compliments among Yemeni EFL Undergraduates
}

\author{
NAIMAH AHMAD AL-GHAMDI \\ Faculty of Arts, \\ Imam Abdulrahman Bin Faisal University, Saudi Arabia \\ NAJEEB TAHER ALMANSOOB \\ Research scholar, \\ Dr. Babasaheb Ambedkar Marathwada University, \\ Siddharth Arts, Com. \& Sci. College, Jafrabad Dist India \\ YASSER ALREFAEE \\ English Department, Faculty of Education, \\ Rada'a, Al-Baydha University, Yemen \\ yasser.alrefaee@gmail.com
}

\begin{abstract}
The purpose of the present study is to investigate into the possibility of pragmatic failure in the L2 production of Yemeni EFL university learners. It, in particular, tackles the L1 negative pragmatic transfer in the speech act of responding to compliments. The participants of the study are thirty Yemeni learners of English representing the target group and two baseline groups: thirty Yemeni Arabic native speakers and thirty American English native speakers. The researchers used a Discourse Completion Task as to collect the relevant data based on six complimenting scenarios. Data were codified into compliment response formulas and analysed statistically via SPSS in terms of the overall frequency counts of the semantic formulas. The results revealed that pragmatic failure is highly evident in the learners' L2 production. L1 negative pragmatic transfer occurred in the response strategies of 'Comment Acceptance', 'Comment History', 'Praise Upgrade', 'Return', 'No Acknowledgement', 'Offer', 'Promise' and 'Wish'. They nearly represent 50\% of the leaners' response utterances. The learners also showed a tendency of positively assimilating their 22 norms in the realization of compliment responses in half of their response utterances.
\end{abstract}

Keywords: Pragmatic Failure; Pragmatic Transfer; Speech Acts; Compliment Responses, Yemeni EFL Learners

\section{INTRODUCTION}

Every language has its own unique system which is governed by a set of linguistic and sociocultural norms. Being inspired by those norms, speakers of a language unconsciously develop a sense of communicative competence which enables them interpret and produce comprehensible and appropriate utterances in their communication process. Similarly, speaking a foreign language appropriately requires students to be aware of the cultural norms underlying the linguistic patterns of that language. It is not only a matter of mastering all the grammatical and structural rules but also of acquiring the knowledge of how language is pragmatically used in the target culture (Leech, 1983). As a result, cross-cultural communication success cannot be achieved unless second language (L2) speakers consider the sociolinguistic norms that take part in the choice of utterance appropriateness such as the purpose of communication which forces the interlocutors to pick suitable linguistic patterns to the context (Al-Khateeb, 2009). In this respect, Yoosefvand and Rasekh (2014) highlighted that "successful communication in a target language requires not only the knowledge of grammar and vocabulary but also pragmatic competence and knowledge about the culture of the target language" (p. 44). Therefore, L2 language teaching requires not only improving the learners' mastery of grammar but also increasing their understandability and awareness of the 
L2 social norms, as the speech act patterns and their restrictions on the social beliefs which are highly dictated by culture (Al-Mansoob, Patil and Alrefaee, 2019). There has been a great consensus among second language acquisition (SLA) scholars that negative pragmatic transfer in which the L2 learners assimilate their first languge (L1) speech acts (apologizing, requesting, inviting, complimenting and so forth) can lead to communication breakdowns due to their lack of L2 pragmatic competence. Meznah (2018), for instance, in a review study on the relation of second language acquisition to language transfer states that "the negative pragmatic transfer occurs usually when the L2 learners erroneously generalized to L2 context from pragmatic knowledge of L1" (p. 18).

Regarding the Yemeni EFL learners, it is reported that they mostly lack pragmatic competence because of the current curriculum instruction that only focuses on promoting their linguistic competence (Al-Sanhani, 2007; Alrefaee, Alghamdi and Almansoob, 2019). As a result, they may develop grammatical competence while most of them face difficulties in selecting appropriate utterances that match real communicative situations. In the same vein, hence, from a functional perspective, the study tracks the possibility of L2 pragmatic failure in the learners' realization of compliment responses through analysing their responses in relation to particular (stimuli) contexts. The researchers approached the complimenting speech act based on the fact that it is as "a kind of culture-bound matter which is directly pertinent to the culture in which one has been nurtured" (Shahsavari, Alimohammadi and Rasekh, 2014, p. 1745). However, this speech act, which is utilized by interlocutors in most of thier speech situations, has not been tackled among the Yemeni learners of English. Hence, the study sheds light into the speech act of responding to compliments, as one of the most investigated speech acts across languages, as an evidence to figure out whether L1 pragmatic transfer occurs positively or negatively. The findings are hopped to be helpful in raising the L2 learners' awareness of the socio-cultural aspects of compliment responses so as to reduce the possibility of cross-cultural communication failure. It is also expected to enrich the pedagogical field with its insights and findings about L1 negative pragmatic transfer with an eye upon the speech act of responding to compliments.

\section{QUESTIONS OF THE STUDY}

This study attempts to find answers for the following questions:

1. What are the most frequently used compliment response strategies among Yemeni EFL learners?

2. Is there any statistically significant differences in the used strategies of responding to compliments between Yemeni English as foreign language learners (YEFLLs) and any of the native groups (Yemeni Arabic native speakers (YANSs) \& American English native speakers (AENSs))?

3. What is the extent of L1 negative pragmatic transfer which leads to pragmatic failure in the learners' L2 production?

\section{LITERATURE REVIEW}

It was nearly 1980s when scholars shed their light around the scope of pragmatics as a very influential source of cross-cultural communication breakdowns. In addition to that, the occurrence of intra-pragmatics studies and the pragmatic perspective toward the learners' native language led to the birth of inter-language pragmatics. As a result, the study of native 
language (NL) influence on target language (TL) learning has been one of the most important trends of inter-language pragmatics (ILP) research. Odlin (1989) said that "cross linguistics influence has considerable potential to affect the course of second language acquisition both inside and outside the classroom" (p. 157). Several researchers prove that negative L1 transfer mostly occurs due to the socio-cultural variations across languages which are the major causes for any pragmatic failure in L2 production. For instance, Takahashi (1996) stated that "inter-cultural miscommunication is often caused by learner's falling down on their L1 socio-cultural norms and conventions in realizing the speech acts in a target language" (p. 189). Any lack of such cross cultural norms and transfer of L1 cultural patterns may cause a serious communication failure or breakdown as "different culture holds different cultural values and beliefs, which are reflected in the use of language and how people communicate" (Alsohaibani, 2017, p. 3). Therefore, there has been a plethora of studies in the scope of inter-language pragmatic that concerned mainly with how non-native speakers differ from native speakers in interpreting and producing a speech act in TL so as to track the causes of pragmatic failure. Beebe, Takahashi and Uliss-Weltz (1990) stated that pragmatic transfer is the "transfer of L1 socio-cultural communicative competence in performing L2 speech acts or any other function of language, where the speaker is trying to achieve a particular function of a language" (p. 56). In this respect, compliment responses have been considered as a highly important speech for inter-language researchers based on the perspective that they are governed by culturally dictated politeness strategies (Golato, 2002; Herbert, 1989, 1990; Holmes, 1988; Wolfson, 1981; Pomerantz, 1978; Chen, 1993). Razi (2013) stated that this speech act is "one type of speech acts worth studying because they can perform different functions. Sometimes using an appropriate compliment and response can help the communication to be successful" (pp. 61-62)

Pomerantz (1978) was the first researcher who analysed compliment responses from a pragmatic perspective. Based on her U.S. data, she divided compliment responses (CRs) into four strategies: acceptance, agreement, rejection, and disagreement. She found that the complimentee faces a conflict between two principles which are either the preference of agreement with the compliments or the avoidance of self-praise. She further stated that the speakers "follow specific patterns" when making and responding to compliments (p. 80).

Since then, several studies compared the speech act of complimenting and other speech acts across languages. Herbert (1986) revised Pomerantz's taxonomy and ended with a three-category, twelve-type taxonomy. He adopted this taxonomy in a contrastive study conducted in $(1989,1990)$ among both Americans and South Africans who were at a college level. The findings showed that the Americans tended to use a high frequency of compliment expressions and a low frequency of compliment acceptance while South Africans used a low frequency of compliment expressions and a high frequency of compliment acceptance. $\mathrm{He}$ illustrated such findings in that each society has its own ideology which links the speakers to some sociocultural perspectives "such as: religion, politics and ecology" (p. 82).

Holmes $(1986,1988)$ developed her own category and adopted it to study the compliment behaviour among New Zealanders. She analysed her data in terms of Brown and Levinson's (1987) theory. She divided her analysis taxonomy into three categories: Accept, Reject, and Deflect or Evade. Her data showed that the most frequent compliment response was 'accept' strategy. She further found that women dealt with the compliment as strategies of maintaining solidarity while men considered them as FTAs. 
TABLE 1. Herbert's Taxonomy of Compliment Responses

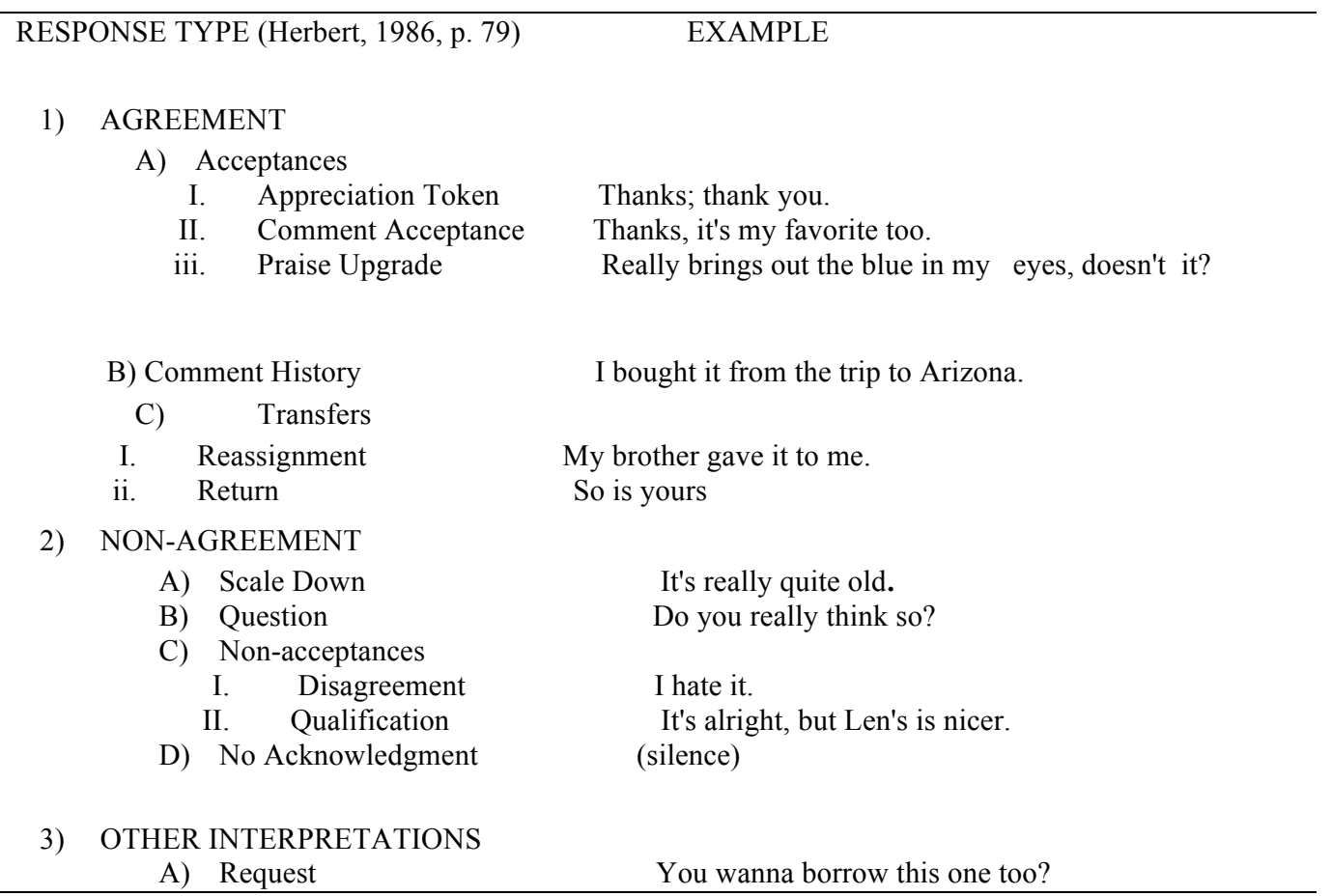

Chen (1993) conducted a contrastive study in the act of responding to compliments among Americans and Chinese. One of the major findings was that the strategies used by Americans were characterised by acceptance governed by Leech's agreement maxims and those strategies adapted by Chinese were characterised by rejection. He further added that such strategies were governed by different social norms of each society. In the light of Herbert's taxonomy, Lorenzo-Dus (2001) conducted a contrastive study on the speech act of compliment responses among both British and Spanish university students. The findings showed that there existed a big similarity between the two societies in responding to compliments. Golato (2003) and Huth (2006) conducted contrastive studies among Americans and German students using conversation analysis. They both concluded that German students preferred to agree with the compliments while Americans tended to use more appreciation tokens such as "thank you". Cedar (2006) conducted another major contrastive study on CRs among Thai learners of English and American speakers. The data collected revealed a significant difference between the two groups in that Americans accepted the compliments and positively replied in the responses whereas the Thai EFL learners refrained from elaborating and tended to use formulaic expressions. Behnam and Amizadeh (2011) studied the realization of compliments and compliment responses in English and Persian TV interviews. They analysed eight interviews of each culture so as to investigate the functions and topics of compliments and the strategies used in the participants' responses to compliments. The study revealed that the Persian participants tended to have a set of similarities and differences to their American counterparts. They further added that the complimenting behavior is highly governed by the cultural norms of the speech community. Morales (2012) conducted a contrastive study across gender on the realization of the speech act of responding to compliments. The researcher used a DCT to collect data from 15 males and 15 females. All of them were in advanced L2 classes. Findings revealed that the two groups of the participants accept the appreciation tokens and return the compliments. Males tended to utilize more implicit CR strategies than females. By then, the scopes of interlangague pragmatics, in general, and the complimenting behiour studies across 
langauges, in particular, have been greatly expanded. Several cross-cultural studies emerged and tackled the specificity and universality of speech acts.

There has been several cross-cultural or interlanguage pragmatic studies conducted among Arabs either in comparison to their American counterparts or to tackle the speech act realization among the EFL learners. In this regard, some of the most popular CR studies that have been conducted by Arabs are outlined briefly in this context. Nelson, Al-Batal and Echols (1996) investigated the compliment response strategies in Syrian Arabic and American English. They interviewed 89 Americans and 32 Syrian participants. They concluded that both Syrians and Americans were more likely to either accept or mitigate the illocutionary force of a compliment. They also added that Americans used more appreciation tokens than Syrians. Farghal and Haggan (2006) conducted an inter-language study on how Kuwaiti EFL undergraduates respond to compliments. In a discourse analysis class, 79 students were asked to give eight instances in which they paid a compliment to a fellow college student in English. The researchers analysed the responses in terms of the context and the frequencies of simple and complex responses. In their conclusion, they proved the strong influence of L1 among Kuwaiti EFL learners in that pragmatic transfer was highly apparent in the frequency of their English compliment responses. Al-Falasi (2007) conducted an interlanguage study among female Emirati learners of English which aimed at finding out whether Emirati learners produce target like compliment responses. The data were collected by means of DCTs and interviews from 10 Emirati EFL learners, 10 Emirati Arabic native speakers and 10 American native speakers. The findings showed that the learners transfer some of their L1 pragmatic norms into the L2 domain. Abdulssattar and Che Lah (2009) conducted an interlanguage study in the realization of compliment responses among Iraqi EFL undergraduates. The data were collected from 25 university students through a written discourse completion test. The findings showed that negative transfer was highly evident mainly in the over use of the word Thanks which is equal to the word Shukran in Arabic. Al-Khateeb (2009) conducted an inter-language study on the speech act of thanking as a compliment response among Palestinian EFL learners. The data were collected from 250 Palestinian EFL learners by using a DCT. She applied all the compliment response strategies so as to pick up the appreciationtoken strategy. Her findings showed that there were significant differences in the ways Arab learners of English apply the act of thanking to those of native English. Alsalem (2015) conducted a comparative study of the speech act of compliment responses between Saudi learners of English and American native speakers. She used a multiple choice discourse completion task of four hypothetical scenarios administered to 104 English native speakers and 71 Saudi EFL learners. She concluded that the learners tended to assimilate their native English counterparts to a great extent. She added that such similarities can be attributed to the fact that the Saudi participants had spent a reasonable amount of time in the U.S. Ebadi and Salan (2015) conducted a study on how Iraqi EFL learners respond to compliments in both Arabic and English. They used a DCT written in English and Arabic to collect data from 100 university learners. They concluded that the learners showed a higher tendency to accept the English compliment than the Arabic one. Females utilized more appreciation tokens for the English compliment other than males and the impact of Arabic formulaic expressions was highly evident in their English responses. Almahameed and Al-Ajalein (2019) studied the pragmatic failure of Jordanian EFL undergraduates. They used a completion test of four language functional categories: accepting compliments, expressing condolence, congratulating and asking for permission. The tool was administered to 30 EFL learners. The findings of the study revealed that pragmatic failure was not highly evident in the learners' responses as they tended to be communicatively competent.

Regarding the Yemeni context, it is worth mentioning that Alrefaee and Al-Ghamdi (2019) conducted a study of negative pragmatic transfer and its relation to proficiency. In this 
study, they compared 40 Yemeni EFL leaners to 40 English native speakers in their realization of the speech act of refusals. They adapted a DCT of twelve scenarios targeting refusals of offers, suggestions, requests and invitations. The findings revealed that negative L1 pragmatic transfer was highly evident especially among low proficient learners. However, the speech act of compliment responses has not been approached by any scholar from a crosscultural perspective. It is highly important to indicate that there is an intra-lingual study conducted among Yemeni Arabic native speakers. It was conducted by Qanbar (2012). She investigated the complimenting behaviour in the Yemeni speech community. She collected about 400 Arabic compliments and concluded that most of the complements paid by Yemenis are formulaic in nature. More importantly, Al-Mansoob, Patil and Alrefaee (2019) conducted a cross cultural study of the speech act of compliments among Yemenis and Americans. The researchers collected the relevant data form 30 Yemeni Arabic native speakers and 30 American English native speakers by means of a discourse completion task. The study concluded that regardless of the big differences occurred between the two cultures, some strategies seemed to be universal across the two native groups. This is to confirm that this current interlanguage study tackles the realization of the speech act of responding to compliments among the Yemeni undergraduate learners of English as a foreign language. Both the Yemeni native compliment norms and the American ones are considered as baseline data meant to be compared to the Yemeni EFL compliment norms so as to see whether L1 negative pragmatic transfer exists or not.

\section{METHODS}

\section{PARTICIPANTS}

Since the study is not an intra-lingual study, the data vary with respect not only to the linguistic background of the participants, but also to their social contexts and cultures. Therefore, the researcher adapted an inter-lingual perspective as the group targeted by the study is only the Yemeni EFL learners. A threefold investigation is needed to be conducted across Yemeni Arabic (monolingual) native speakers, American English native speakers and the Yemeni EFL university learners. The target group of the study consisted of thirty Yemeni students of English. All were systematically selected from level four learners studying at the Department of English, Faculty of Education (Sana'a University). The baseline data consisted of two groups: thirty Yemeni Arabic speakers and thirty American English native speakers. Yemenis were randomly chosen from the Department of Arabic, Faculty of Education, Sana'a University. A non-probability sample of thirty Americans have responded to the Discourse completion Task (DCT). All were from different departments at Southern Illinois University at Carbondale. Their response sheets were mailed directly to the researcher.

\section{INSTRUMENT}

Keeping in mind the findings of the major studies on pragmatic transfer, the researcher applied a Discourse Completion Task that consists of six stimuli. The compliment topics, based on which the scenarios were weighted, are beyond the scope of this study but the researcher put them into consideration so as to vary the contextual occurrence of compliments that are authentic across both English and Arabic. DCTs are "written questionnaires including a number of brief descriptions, followed by a short dialog with an empty slot for the speech act under study" (Kasper, 1992, p. 221). This tool was originally developed by Blum-Kulka (1982) and has been widely applied by cross cultural scholars such as (Enssaif, 2005; Al-Khateeb, 2009). 


\section{DATA COLLECTION PROCEDURES}

DCT was initially administered on thirty participants, as the target group, who were systematically selected out of the lists of the fourth level learners at the Department of English (Faculty of Education - Sana'a University) by one of the researchers with the help of some lecturers at the Department of English. The tool hypothetical scenarios (the stimuli) were initially translated into Arabic so as to be administered among the native Arabic participants. To guarantee an accurate representation of the instrument, the researchers sent the Arabic version to a pragmatics specialist at Thamar University and a Yemeni Translator at the Red Cross Organisation to translate it back into English so as to be compared to the original version. Such systematic procedures were under the consultation of three translation specialists. After taking the permission of the head of the Arabic department and selecting thirty native speakers, the DCT was also administered by the one of the researchers in the faculty. Similarly, a version emailed again to two Yemeni EFL scholars in the U.S, as to gather the other baseline data from thirty American native speakers.

\section{DATA ANALYSIS PROCEDURES}

After gathering the relevant data from 90 participants, the response utterances of each group were coded into semantic formulas respectively. The researchers mainly used the SPSS statistical program (20.0 version) so as to pinpoint the similarities and differences across the target group and the baseline groups and measure the possibility of pragmatic failure in the use L2 CRs by the learners. First, the frequency distributions of the strategies of CRs of each group were elaborated as to find out the overall used strategies across the three groups. Second, the One-way ANOVA test was used to find out the significant differences in the mean uses of CRs across either the target group and any of the baseline groups or the native baseline groups themselves. Thirdly, the Post hoc multi-comparison tests of Scheffe were used mainly to pinpoint towards who of the baseline native participants the YEFLLs showed closer tendencies in the use of CRs.

\section{RESULTS AND DISCUSSION}

\section{THE OVERALL USED STRATEGIES}

This section is hoped to answer the first question which is about the most frequently used compliment response strategies among the participants which paves the ground for a thorough contrastive analysis across the three groups as to examine the extent of L1 pragmatic transfer in the performance of the learners. Therefore, the following table reveals the overall used strategies across the three groups with their frequencies and percentages.

TABLE 2. The Overall Used Compliment Response Strategies Across the Groups

\begin{tabular}{|c|c|c|c|c|c|c|c|}
\hline \multirow{2}{*}{\multicolumn{2}{|c|}{$\begin{array}{l}\text { COMPLIMENT RESPONSE } \\
\text { STRATEGIES }\end{array}$}} & \multicolumn{2}{|c|}{ YEFLLs } & \multicolumn{2}{|c|}{ AENSs } & \multicolumn{2}{|c|}{ YANSs } \\
\hline & & $\mathrm{F}$ & $\%$ & $\mathrm{~F}$ & $\%$ & $\mathrm{~F}$ & $\%$ \\
\hline 1 & Appreciation Token & 143 & $42.7 \%$ & 160 & $53.9 \%$ & 65 & $18.7 \%$ \\
\hline 2 & Return & 98 & $29.2 \%$ & 14 & $4.7 \%$ & 82 & $23.6 \%$ \\
\hline 3 & Comment Acceptance & 16 & $4.8 \%$ & 35 & $11.8 \%$ & 22 & $6.3 \%$ \\
\hline 4 & Offer & 11 & $3.3 \%$ & 0 & $0 \%$ & 14 & $4 \%$ \\
\hline 5 & Wish & 11 & $3.3 \%$ & 0 & $0 \%$ & 21 & $6 \%$ \\
\hline 6 & Question & 10 & $3 \%$ & 5 & $1.7 \%$ & 9 & $2.6 \%$ \\
\hline 7 & Disagreement & 8 & $2.4 \%$ & 9 & $3 \%$ & 12 & $3.4 \%$ \\
\hline 8 & Gratitude To God & 8 & $2.4 \%$ & 0 & $0 \%$ & 34 & $9.8 \%$ \\
\hline 9 & Comment History & 5 & $1.5 \%$ & 39 & $13.1 \%$ & 4 & $1.1 \%$ \\
\hline 10 & Promise & 5 & $1.5 \%$ & 0 & $0 \%$ & 10 & $2.9 \%$ \\
\hline
\end{tabular}




\begin{tabular}{|c|c|c|c|c|c|c|c|}
\hline 11 & Qualification & 5 & $1.5 \%$ & 4 & $1.3 \%$ & 5 & $1.4 \%$ \\
\hline 12 & No Acknowledgement & 3 & $0.9 \%$ & 2 & $0.7 \%$ & 9 & $2.6 \%$ \\
\hline 13 & Praise Upgrade & 3 & $0.9 \%$ & 12 & $4 \%$ & 7 & $2 \%$ \\
\hline 14 & Request & 3 & $0.9 \%$ & 4 & $1.3 \%$ & 2 & $0.6 \%$ \\
\hline 15 & Fearing Devil-Eye & 2 & $0.6 \%$ & 0 & $0 \%$ & 5 & $1.4 \%$ \\
\hline 16 & Scale Down & 2 & $0.6 \%$ & 10 & $3.4 \%$ & 12 & $3.4 \%$ \\
\hline 17 & Invocation & 1 & $0.3 \%$ & 0 & $0 \%$ & 32 & $9.2 \%$ \\
\hline 18 & Reassignment & 1 & $0.3 \%$ & 3 & $1 \%$ & 3 & $0.9 \%$ \\
\hline
\end{tabular}

It seems that there are some variations across the responses of the three groups. More importantly, this forces the researchers to apply a more systematic technique so as to tackles the similarities and differences across the participating groups. It is worth mentioning here that the learners mostly used the strategies of 'Appreciation Token' as in saying: "Thanks so much" and 'Return' as in saying: "Yours is nicer". Their response-utterances are restricted to such strategies with the total percentage of $72 \%$ while $28 \%$ of their responses is represented by the other sixteen strategies as shown in Table (1) above. In this context, the overall used strategies across the baseline native counterparts are further shown in the following details so as to be compared to the target group and answer the study questions so as to get clear-cut evidences for pragmatic failure in the CR strategies utilized by the learners.

\section{THE STATISTICALLY SIGNIFICANT DIFFERENCES ACROSS THE PARTICIPANTS AND THE LEARNERS' L1 PRAGMATIC TRANSFERABILITY IN THEIR L2 DOMAIN}

A scientific statistical approach has been further adapted so as to mainly answer the second question of the study which is about the pragmatic similarities and differences among the groups. Such findings further provide the researcher with clear-cut evidences about the possibility of L1 pragmatic transfer which is the core answer of the third question. Thus, the One-way ANOVA test was used so as to find out the significant differences in the mean uses of CR strategies across the participants of the three groups (YEFLLs, YANSs and AENSs).

TABLE 3. The One-way ANOVA of the Lack of Significant Differences across the groups

\begin{tabular}{llccccc}
\hline CRs strategies & Source of Variance & $\begin{array}{c}\text { Sum of } \\
\text { Squares }\end{array}$ & df & Mean Square & F & Sig. \\
\hline Reassignment & Between Groups & .089 & 2 & .044 & .607 & 0.547 \\
Question & Between Groups & .467 & 2 & .233 & 1.061 & 0.351 \\
Qualification & Between Groups & .022 & 2 & .011 & .082 & 0.921 \\
Disagreement & Between Groups & .289 & 2 & .144 & .649 & 0.525 \\
Request & Between Groups & .067 & 2 & .033 & .361 & 0.698 \\
Fearing Devil-Eye & Between Groups & .422 & 2 & .211 & 3.044 & 0.053 \\
\hline
\end{tabular}

It is shown in this table that there did not exist any statistically significant differences across the groups with respect to the response strategies of 'Reassignment', 'Question', 'Qualification', 'Disagreement', 'Request' and 'Fearing Devil-Eye'. What is interesting here is that none of these strategies is of the most used strategies across either the target group or the baseline groups which reveals that there appeared a great variation across the participating groups. However, the similarities appeared in this respect might be because they are universal strategies except the 'Fearing Devil-Eye' strategy which seems to be culturally specific to the Arabs as the Americans never used it in their responses. But, the difference is not statistically significant due to the rare use of the strategy by Arabs. In addition, as for the YEFLLs, the lack of significant differences with the native baseline groups can be also due to being pragmatically competent in their L2. On the other hand, the statistically significant difference in the performance of the compliment responses across the participating groups are as shown in the following table: 
3L: The Southeast Asian Journal of English Language Studies - Vol 25(4): 1 - 14

http://doi.org/10.17576/3L-2019-2504-14

TABLE 4. The One-way ANOVA of the Existence of Significant Differences across the groups

\begin{tabular}{|c|c|c|c|c|c|c|}
\hline CRs strategies & Source of Variance & $\begin{array}{l}\text { Sum of } \\
\text { Squares }\end{array}$ & $\mathrm{df}$ & $\begin{array}{c}\text { Mean } \\
\text { Square }\end{array}$ & $\mathrm{F}$ & Sig. \\
\hline Appreciation Token & Between Groups & 171.089 & 2 & 85.544 & 54.643 & $0.000 * *$ \\
\hline Comment Acceptance & Between Groups & 6.289 & 2 & 3.144 & 6.289 & $0.003 * *$ \\
\hline Praise Upgrade & Between Groups & 1.356 & 2 & .678 & 3.862 & $0.025 *$ \\
\hline Comment History & Between Groups & 26.467 & 2 & 13.233 & 64.199 & $0.000 * *$ \\
\hline Return & Between Groups & 132.622 & 2 & 66.311 & 64.676 & $0.000 *$ \\
\hline Scale Down & Between Groups & 1.867 & 2 & .933 & 5.161 & $0.008 * *$ \\
\hline No Acknowledgement & Between Groups & .936 & 2 & .468 & 3.704 & $0.029 *$ \\
\hline Gratitude To God & Between Groups & 21.067 & 2 & 10.533 & 22.171 & $0.000 * *$ \\
\hline Invocation & Between Groups & 22.067 & 2 & 11.033 & 27.557 & $0.000 * *$ \\
\hline Offer & Between Groups & 3.622 & 2 & 1.811 & 7.024 & $0.001 * *$ \\
\hline Promise & Between Groups & 1.667 & 2 & .833 & 6.692 & $0.002 * *$ \\
\hline Wish & Between Groups & 7.356 & 2 & 3.678 & 9.073 & $0.000 * *$ \\
\hline
\end{tabular}

(**) It means that the value is significant at the 0.01 level

(*) It means that the value is significant at the 0.05 level

It is shown in Table (3) above that there are statistically significant differences across the strategies of 'Appreciation Token', 'Comment Acceptance', 'Praise Upgrade', 'Comment History', 'Return', 'Scale down', 'No Acknowledgement', 'Gratitude to God', 'Invocation', 'Offer', 'Promise', and 'Wish' with f/ values of (54.643, 6.289, 3.862, 64.199, 64.676, 5.161, $3.704,22.171,27.557,7.024,6.692$, and 9.073) respectively. As all these values occur with significance levels that range between 0.05 and 0.01 , it derives the researcher to use Post hoc multi-comparisons of Scheffe in order to figure out in favor of who such differences occur across the participants of the three groups as shown in the following table:

TABLE 5. Post hoc Multiple-Comparison Tests of Scheffe for the CRs

\begin{tabular}{|c|c|c|c|c|c|}
\hline \multirow[t]{2}{*}{ Dependent Variable } & \multirow[t]{2}{*}{ (I) Group } & \multirow[t]{2}{*}{ Mean } & \multicolumn{3}{|c|}{$\begin{array}{l}\text { Mean Difference (I-J) } \\
\text { (J) Group }\end{array}$} \\
\hline & & & YANSs & YEFLLs & AENSs \\
\hline \multirow[t]{3}{*}{ Appreciation Token } & YANSs & 2.1667 & - & $-2.60000(*)$ & $-3.16667(*)$ \\
\hline & YEFLLs & 4.7667 & - & - & -.56667 \\
\hline & AENSs & 5.3333 & - & - & - \\
\hline \multirow[t]{3}{*}{ Comment Acceptance } & YANSs & .7333 & - & .20000 & -.43333 \\
\hline & YEFLLs & .5333 & - & - & $-.63333(*)$ \\
\hline & AENSs & 1.1667 & - & - & - \\
\hline \multirow[t]{3}{*}{ Praise Upgrade } & YANSs & .2333 & - & .13333 & -.16667 \\
\hline & YEFLLs & .1000 & - & - & $-.30000(*)$ \\
\hline & AENSs & .4000 & - & - & - \\
\hline \multirow[t]{3}{*}{ Comment History } & YANSs & .1333 & - & -.03333 & $-1.16667(*)$ \\
\hline & YEFLLs & .1667 & - & - & $-1.13333(*)$ \\
\hline & AENSs & 1.3000 & - & - & - \\
\hline \multirow[t]{3}{*}{ Return } & YANSs & 2.7333 & - & -.53333 & $2.26667(*)$ \\
\hline & YEFLLs & 3.2667 & - & - & $2.80000(*)$ \\
\hline & AENSs & .4667 & - & - & - \\
\hline \multirow[t]{3}{*}{ Scale Down } & YANSs & .4000 & - & $.33333(*)$ & .06667 \\
\hline & YEFLLs & .0667 & - & - & -.26667 \\
\hline & AENSs & .3333 & - & - & - \\
\hline \multirow[t]{3}{*}{ No Acknowledgement } & YANSs & .3000 & - & .20000 & $.23103(*)$ \\
\hline & YEFLLs & .1000 & - & - & .03103 \\
\hline & AENSs & .0690 & - & - & - \\
\hline \multirow[t]{3}{*}{ Gratitude To God } & YANSs & 1.1333 & - & $.86667(*)$ & $1.13333(*)$ \\
\hline & YEFLLs & .2667 & - & - & .26667 \\
\hline & AENSs & .0000 & - & - & - \\
\hline \multirow[t]{3}{*}{ Invocation } & YANSs & 1.0667 & - & $1.03333(*)$ & $1.06667(*)$ \\
\hline & YEFLLs & .0333 & - & - & .03333 \\
\hline & AENSs & .0000 & - & - & - \\
\hline \multirow[t]{2}{*}{ Offer } & YANSs & .4667 & - & .10000 & $.46667(*)$ \\
\hline & YEFLLs & .3667 & - & - & $.36667(*)$ \\
\hline
\end{tabular}




\begin{tabular}{lccccc}
\hline \multirow{3}{*}{ Promise } & AENSs & .0000 & - & - & - \\
& YANSs & .3333 & - & .16667 & $.33333\left(^{*}\right)$ \\
\multirow{3}{*}{ Wish } & YEFLLs & .1667 & - & - & .16667 \\
& AENSs & .0000 & - & - & - \\
& YANSs & .7000 & - & .33333 & $.70000\left(^{*}\right)$ \\
& YEFLLs & .3667 & - & - & .36667 \\
\hline
\end{tabular}

(*) The mean difference is significant at the 0.05 level

It is clear from the table above that the results of the CR strategies, through which there appear significant differences across the participants, are as follows:

a) There seems a statistically significant difference in the employment of 'Appreciation Token' between YANSs and YEFLLs at a mean difference of $(-2.60)$ which is found to be in favor of YEFLLs since they scored a higher mean at the value of (4.77). However, there is no statistically significant difference between YEFLLs and AENSs. This reveals that YEFLLs tended to use the L2 norms appropriately which also evidently indicates that they showed a good level of L2 pragmatic competence.

b) The Table (4) also shows that there is a statistically significant difference between YEFLLs and AENSs at a mean difference of (-.63) in that AENSs are found to use more 'Comment Acceptance' responses at the mean of (1.17) than YEFLLs who scored the mean of (.53). What is mostly important here is that there is no statistically significant difference between YEFLLs and YANSs as YEFLLs negatively tended to assimilate their L1 patterns to the point that can cause a serious pragmatic failure in their L2 communication. This might be due to receiving a compliment as a Face Threatening Act as they tended to use less comment acceptance utterances and appeared to be closer to their L1 counterparts. Enssiaf (2005) in her contrastive study among Saudis and Americans illustrated such findings saying that "participants avoided agreeing with the speaker because accepting the compliment might be interpreted as arrogance" (p. 58).

c) There is a statistically significant difference between YEFLLs and AENSs in the employment of 'Praise Upgrade' at a mean difference of (-.30) in that YEFLLs showed a less tendency of using this strategy (.10) than AENSs who scored a higher mean (.40). Whereas no statistically significant difference occurred between YANSs and YEFLLs. In this respect, it is evidently revealed that the Yemeni EFL learners negatively tended to assimilate their L1 norms which might be due to their lack of L2 pragmatic competence.

d) Regarding the 'Comment History' strategy, there seems a significant difference between YEFLLs and AENSs at a mean difference of (-1.13) as YEFLLs got only the mean of (.17). Such statistically significant differences did not occur between YEFLLs and their L1 counterparts which negatively indicates that they transfer their L1 pragmatic norms into the $\mathrm{L} 2$ context.

e) There is a statistically significant difference in the employment of the 'Return' strategy between YEFLLs and AENSs at a mean difference of (2.80) in that YEFLLs scored the mean of (3.27) which is higher than the AENSs did. However, there did not exist any significant difference between YEFLLs and their L1 counterparts. They both used 'Return' as the second most used strategy. It might be because they feel embarrassed to accept the full force of the compliment and they mitigate it by giving it back to the complimenter.

f) There is a statistically significant difference in the employment of 'Scale Down' between YANSs and YEFLLs at a mean difference of (.33) in that YANSs got the mean of (.40) while YEFLLs got a very low mean which is at the value of (.07).

However, no significant difference is shown between YEFLLs and AENSs though there seems a difference in the means scored by the two groups in that AENSs got the mean use of (.33). This reveals that YEFLLs positively assimilated their L2 pragmatic norms. 
g) As for the 'No Acknowledgement' strategy, YEFLLs got the mean of (.10) which shows that there is not any statistically significant difference between them and any of the two baseline groups. Therefore, being at a moderate level between the two baseline groups indicates that the norms they used are an amalgam of the L1 and the L2 pragmatic features which further indicates that the learners are not pragmatically competent with respect to their utilization of these strategies.

h) There is a statistically significant difference in the employment of 'Gratitude to God' strategy between YANSs and YEFLLs at a mean difference of (.87) in that YEFLLs got the mean of (.27) which is considerably very low. But such a statistically significant difference did not exist between YEFLLs and AENSs which indicates that they (YEFLLs) greatly tended to assimilate their L2 counterparts in the use of this strategy. This further indicates that this strategy is mainly specific to the Arabic culture. In the same vein, AlKhateeb (2009) in her study of the speech act of thanking among Palestinians concluded that "because of their strong ties with religion, Arabs have their faith in God (Allah) deeply embedded with their speech acts. This is why most of the semantic formulas used as compliment response are religious in content" (p. 85).

i) There is a statistically significant difference in the employment of 'Invocation' between YANSs and YEFLLs at a mean difference of (1.03) in that YEFLLs rarely used this strategy. They got only the mean of (.03) which represents that they used 'Invocation' only one time in their response utterances. Consequently, no significant difference existed between them and their American counterparts. What is interesting in this respect is that YEFLLs showed a good level of L2 pragmatic competence as they positively assimilated their L2 counterparts in the employment of this strategy which might be due to being aware that the target language speech community is not religious in nature. This strategy also seems to be culturally specific since it was only used by Arabs. As for Al-Khateeb (2009), she classified this technique under the acceptance formulas which represents everyday life expressions. She stated that Palestinians "used semantic formulas that showed their strong ties with religion and everyday life like May Allah bless you and give you a happy life" (p. 66).

j) There is a statistical significant difference in the employment of 'Offer' between YEFLLs and AENSs at a mean difference of (.37) in that YEFLLs got the mean of (.37). Above all, there did not exist any statistical significant difference between YEFLLs and YANSs which means that YEFLLs negatively resembled their L1 counterparts in the use of this strategy. This might be due to their expectation that 'Offer' is a universal compliment response strategy and tended to show a more polite behavior towards the complimenter. Such influences of L1 can result in a communication breakdown in the L2 context.

k) As for the 'Promise' strategy, there did not exist any statistically significant differences between YEFLLs and any of the baseline groups. What is mostly important is that negative L1 pragmatic transfer is evident in the utilization of this strategy by the Yemeni learners of English and they still lack the L2 pragmatic competence despite being linguistically competent. This strategy further seems to be culturally specific to Arabic since the Americans showed a tendency of not using promise utterances.

1) With respect to the 'Wish' strategy, the target group (YEFLLs) did not reveal any statistically significant difference with any of the baseline groups as they showed a rare use of wish utterances. Therefore, L1 negative pragmatic transfer is highly evident in this respect which might be due to their lack of the L2 pragmatic competence. 


\section{CONCLUSION}

The major findings of the study concludes that negative L1 pragmatic transfer among YEFLLs was evident in the employment of the compliment response strategies of 'Comment Acceptance', 'Comment History', 'Praise Upgrade', 'Return', 'No Acknowledgement', 'Offer', 'Promise' and 'Wish'. Since these strategies nearly represent the percentage of $(45.4 \%)$ of the total used CR strategies, it may result in creating a misunderstanding between the learners and the native English interlocutors. Whereas, the most frequently used compliment response strategies among Yemeni EFL learners are only 'appreciation token' and 'return'. The study also reveals that the YEFLLs appropriately used the CR strategies of 'Reassignment', 'Question', 'Qualification', 'Disagreement', 'Request', 'Fearing Devil-Eye', 'Appreciation Token', 'Scale Down', 'Gratitude to God' and 'Invocation'. They showed a good level of L2 pragmatic competence as they assimilated their L2 norms at the percentage of $(54.7 \%)$ of the total used strategies. This can be either an evidence of a positive pragmatic transfer or an evidence which supports the universalists' claim that there is a set of norms that world languages share in common in the realization of speech acts (Al-Mansoob, Patil \& Alrefaee, 2019). But, still their tendency to assimilate their L1 norms is apparent and can cause a serious pragmatic failure that hinders the process of effective communication when interacting with English native speakers. An interesting result that is further encountered in this study is that the learners mostly used the compliment strategies of 'Appreciation Token' and 'Return' at the percentage of $71 \%$ which indicates that their responses are formulaic and restricted to specific semantic patterns. However, they deviated from the L2 norms in this respect as their American counterparts utilized the strategies of 'Appreciation Token' and 'Return' at the percentage of 59\% of their total response utterances.

To sum up, the Yemeni EFL learners' tendency of assimilating their L1 counterparts in their realizations of L2 compliment responses indicates that they are pragmatically incompetent regardless of being linguistically competent. They deviated to a serious extent from the appropriate socio-pragmatic L2 norms which have nothing to do with language competency but rather assimilation of cultural patterns and norms of behaviors such as the politeness norms. Such a discouraging performance might also be due to the learners' unawareness of the L2 pragmatics and cultural differences. Thus, this study signals the impact of cultural gab in generating pragmatic failure, qualitatively and quantitatively. It is the effect in light of this clash of cultures that responding to compliments was put to trail. Moreover, it seems learners struggle to escape the embarrassment by responding to compliments using frozen or formulaic responses. Hence, it is safe to say that the wider the cultural gap between the two codes, as between Arabic and English, the more awkward responding to compliments assimilation.

\section{REFERENCES}

Abdulssattar. H. \& Che Lah. S. (2009). A Study of compliment responses in English among Iraqi postgraduates at USM. Retrieved from: http://www.academia.edu/1069157/A Study of Compliment Responses in English among Iraqi Po stgraduates at USM

Al-Falasi, H. (2007). Just Say "Thank You”: A study of compliment responses. The Linguistics Journal, 2 (1), $28-42$.

Al-Khateeb, S. (2009). The Speech Act of Thanking as a Compliment Response as Used by the Arab Speakers of English: a Comparative Inter-cultural Study. Palestine: An-Najah National University. Retrieved from http://www.sholars.najah.edu/site/scholar.najah.edu/files/allthesis/688.pdf

Almahameed, Y. S. \& Al-Ajalein, M. M. (2019). Pragmatic Failure Committed by Jordanian Undergraduate EFL Learners. International Journal. 7(1), 54-60. 
Al-Mansoob, N. T., Patil, K. S. \& Alrefaee, Y. (2019). A Cross-cultural Study of The Speech Act of Compliments in American English and Yemeni Arabic. LANGKAWI Journal.5(1), 1-12. http://dx.doi.org/10.31332/lkw.v5i1.1271

Alrefaee, Y. Alghamdi, N. Almansoob, N. (2019). A Sociolinguistic Study of the Realization of Refusals among Yemeni EFL Learners. International Journal of English Linguistics. 9(5), 172-185. doi:10.5539/ijel.v9n6p172

Alrefaee, Y. Alghamdi, N. (2019). Refusals among Yemeni EFL Learners: A Study of Negative Pragmatic Transfer and Its Relation to Proficiency. Asian EFL Journal. 25, 5-1, 191-214.

Alsalem, N. K. (2015). Compliment responses: A comparison of Saudi English learners and native speakers of American English in an academic environment (Master's thesis). Sothern Illinois University, Carbondale, IL.

Al-Sanhani, H. (2007). The Effect of Instruction on Developing the Pragmatic Competence of EFL Yemeni Learners. Unpublished Master's Dissertation. Sana'a University. Yemen.

Alsohaibani, A. (2017). Influence of Religion on Language Use: a sociopragmatic study on the influence of religion on speech acts performance. (Unpublished doctoral thesis). University of East Anglia. England.

Beebe, L. M., Takahashi, T. \& Uliss-Weltz, R. (1990). Pragmatic Transfer in ESL Refusals. In R. C. Scarcelle, E. Anderson, \& S. C. Krashen (Eds.), Developing Communicative Competence in a Second Language (pp. 55-73). New York: Newbury House.

Behnam, B. \& Amizadeh, N. (2011). A comparative study of the compliments and compliment responses between English and Persian TV interviews. 3L: Language, Linguistics, Literature. 17(1), 65-78

Blum-Kulka, S. (1982). Learning How to Say What You Mean in a Second Language: A Study of Speech Act Performance of Learners of Hebrew as a Second Language. Applied Linguistics. 3,29-59.

Brown, P. \& Levinson, S. (1987). Politeness: Some Universals in Language Usage. Cambridge University Press, Cambridge.

Cedar, P. (2006). Thai and American Responses to Compliments in English. The Linguistics Journal. 1(2), 6-28.

Chen, R. (1993). Responding to Compliments: A Contrastive Study of Politeness Strategies between American English and Chinese Speakers. Journal of Pragmatics. 20, 49-70.

Ebadi, S. \& Salan, A. R. (2015). Using compliment responses in Arabic and English: Focusing on male and female EFL learners in Iraq. Journal of Applied Linguistics and Language Research, 2(7), 157-178.

Enssaif, Z. (2005). Compliment behavior: Strategies and realizations in English and Arabic: A case study of female students of the English department, King Saud University. (Unpublished master's thesis). King Saud University, KSA.

Farghal, M. \& Haggan, M. (2006). Compliment Behavior in Bilingual Kuwaiti College Students. The International Journal of Bilingual Education and Bilingualism. 9(1), 94-118. https://doi.org/10.1080/13670050608668632

Golato, A. (2002). German compliment responses. Journal of Pragmatics. 547-571.

Golato, A. (2003). Studying Compliment Responses: A Comparison of DCTs and Recordings of Naturally Occurring Talk. Applied Linguistics. 24(1), 90-121.

Herbert, K. (1986). Say "thank you” or Something. American Speech. 61(1), 76- 88.

Herbert, R. K. (1989). The ethnography of English compliments and compliment responses. Contrastive Pragmatics. 3-35.

Herbert, K. (1990). Sex-based Differences in Compliment Behavior. Language in Society. 19, 201-224.

Holmes, J. (1986). Compliments and compliment responses in New Zealand English. Anthropological Linguistics. 28(4), 485-508.

Holmes, J. (1988). Paying compliments: a sex preferential positive politeness strategy. Journal of Pragmatics. $12(3), 445465$.

Huth, T. (2006). Negotiation Structure and Culture: L2 Learners' Realization of L2 Compliment Response Sequences in Talk-in-interaction. Journal of Pragmatics. 38, 2025-2050.

Kasper, G. (1992). Pragmatic Transfer. Second Language Research. 8, 203-231.

Leech, G. (1983). Principles of Pragmatics. New York: Longman.

Lorenzo-Dus, N. (2001). Compliment Responses among British and Spanish University Students: A Contrastive Study. Journal of Pragmatics. 33, 7-127.

Meznah, A. (2018). Investigating the negative impact of pragmatic transfer on the acquisition of English pragmatic as perceived by L2 Learners: A review. International Journal of English and Literature. 9(3), 18-24. https://doi.org/10.5897/IJEL2018.1151

Morales, R. C. (2012). Compliment responses across gender in Philippine context. 3L: Language, Linguistics, Literature. 18(1), 47-60.

Nelson, G., Al-Batal, M. \& Echols, E. (1996). Arabic and English Compliment Responses: Potential for Pragmatic Failure. Applied Linguistics. 17(4), 411-432. 
Odlin, T. (1989). Language Transfer. Cambridge: CUP.

Pomerantz, A. M. (1978). Compliment response: Notes on the cooperation of multiple constraints. In J.N. Schenkein (Ed.). Studies in the Organisation of Conversational Interaction (pp. 79-112). New York: Academic Press.

Qanbar, N. (2012). Compliments in the Yemeni Society: A Sociolinguistic Perspective. GEMA Online ${ }^{\circledR}$ Journal of Language Studies. 12(3), 999-1017.

Razi, N. (2013). A contrastive study of compliment responses among Australian English and Iranian Persian speakers. Procedia-Social and Behavioral Sciences. 70, 61-66.

Shahsavari, S., Alimohammadi, B. \& Rasekh, A. E. (2014). Compliment Responses: A Comparative Study of Native English Speakers and Iranian L2 Speakers. Procedia - Social and Behavioral Sciences, 98, 1744-1753. https://doi.org/10.1016/j.sbspro.2014.03.602

Takahashi, S. (1996). Pragmatic Transferability. Studies in Second Language Acquisition. 18(2), 189-223.

Wolfson, N. (1981). Compliments in cross-cultural perspective. TESOL Quarterly. 15(2), 117-24.

Yoosefvand, A. \& Rasekh, A. E. (2014). A comparative study of Gratitude Speech Act between Persian and English Speakers. Journal of Applied Linguistics and Language Research. 1(2), 44-61. 